\title{
Nebulised sodium cromoglycate in infancy: airway protection after deterioration
}

\author{
C O’Callaghan, A D Milner, A Swarbrick
}

\begin{abstract}
Over a two year period 100 infants with histories of wheeze were challenged with nebulised water. They were sedated and lung function measured by total body plethysmography. Thirteen of the 53 infants who developed bronchoconstriction after challenge with nebulised water were given nebulised sodium cromoglycate and rechallenged with nebulised water. All infants were initially challenged with normal saline, after which there was no significant change in lung function. After challenge with nebulised water and sodium cromoglycate there were significant decreases in specific conductance compared with those found after challenge with normal saline. After rechallenge with nebulised water there was no deterioration in lung function. Although sodium cromoglycate caused a deterioration in lung function in these infants, it protected their airways from challenge with nebulised water.
\end{abstract}

Nebulised sodium cromoglycate ${ }^{1}$ and salbutamol $^{2}$ have little clinical effect on the airways of children under the age of 1 year. Recently, however, nebulised salbutamol has been shown to protect against the bronchoconstricting action of nebulised water in infants, ${ }^{3}$ but it may cause a transient paradoxical deterioration in the lung function of wheezy infants. ${ }^{4}$ The cause of this deterioration is not known, but may be associated with the acidity, preservatives, or osmolality of the nebulised solution, or with the drug itself.

The aim of this study was to assess how much nebulised sodium cromoglycate protected the airways of wheezy infants from challenge with nebulised water. The immediate reaction to the sodium cromoglycate nebuliser solution, which is hypo-osmolar was assessed.

Patients and methods

During an 18 month period 100 infants with histories of wheeze were challenged with nebulised water. Thirteen of the 53 infants who developed bronchoconstriction after the challenge were entered into this study (table 1). At the time of the investigation two infants had mild wheeze. The others were clinically well and it was at least two months since their bronchiolitic illness. No infant had had an upper respiratory tract infection in the two weeks leading up to the study.

The infants were sedated with chloral hydrate $120 \mathrm{mg} / \mathrm{kg}$ and thoracic gas volume and airways resistance were measured by total body plesthysmography as previously described. ${ }^{5}$ Baseline measurements of thoracic gas volume and airways resistance were made. Ultrasonically nebulised normal saline $\left(21^{\circ} \mathrm{C}\right.$, volume $\left.150 \mathrm{ml}\right)$ from an intersurgical Variosonic nebuliser at setting 3 was given to the infants by face mask for two mintues at a flow rate of $5 \mathrm{l} /$ minute. Thoracic gas volume and airways resistance were measured immediately after nebulisation and at five minute intervals until the readings were stable (defined as no change over a five minute period). A dense mist occasionally escaped from the space between the mask and the face in the first few seconds of nebulisation owing to an inadequate seal. The mask was readjusted and the study restarted with an adequate seal.

Infants were given ultrasonically nebulised water from the same nebuliser $\left(21^{\circ} \mathrm{C}\right.$ volume, $150 \mathrm{ml}$ ) for two minutes. Thoracic gas volume and airways resistance were again measured at regular intervals until readings were stable. The infants who developed signs of bronchoconstriction after being given nebulised water were given nebulised sodium cromoglycate through a Unicorn nebuliser chamber (Medic AID) (volume $2 \mathrm{ml}$ of $1 \%$ sodium cromoglycate). A flow rate of $4.5 \mathrm{l} / \mathrm{minute}$ was maintained for five minutes. Thoracic gas volume and airways resistance were measured until stable.

Fifteen minutes after receiving the nebulised sodium cromoglycate the infants were chal-
Department of Child Health, University Hospital, Queen's Medical Centre, Nottingham NG7 2UH C O'Callaghan

A D Milner

A Swarbrick

Correspondence to: Dr O'Callaghan.

Accepted 8 November 1989

Table 1 Details of 13 patients

\begin{tabular}{rrllrr}
\hline Case No & Age (months) & Sex & $\begin{array}{l}\text { History of confirmed respiratory } \\
\text { syncytial virus bronchiolitis }\end{array}$ & Family history of atopy & $\begin{array}{l}\text { Weight } \\
(\mathrm{kg})\end{array}$ \\
\hline 1 & 3 & Female & No & Yes & $7 \cdot 6$ \\
2 & 8 & Female & No & Yes & $8 \cdot 5$ \\
3 & 4 & Male & Yes & Yes & No \\
4 & 13 & Male & Yes & No & $12 \cdot 0$ \\
5 & 12 & Male & No & Yes & $10 \cdot 7$ \\
6 & 12 & Male & Yo & Yes & $9 \cdot 2$ \\
7 & 19 & Male & Yes & 10 \\
8 & 13 & Male & Yes & Yes & $9 \cdot 2$ \\
9 & 9 & Male & No & Yes & $9 \cdot 4$ \\
10 & 9 & Male & Yes & No & $10 \cdot 4$ \\
11 & 6 & Male & Yes & No & $9 \cdot 4$ \\
12 & 7 & Male & Yes & & $11 \cdot 9$ \\
13 & 12 & & & \\
\hline
\end{tabular}


lenged again with two minutes of nebulised water. Four of the patients were rechallenged with nebulised water from an ultrasonic nebuliser. On this occasion the mist was given for four minutes (a double dose). All patients had oxygen saturation measured and electrocardiographic monitoring throughout.

The osmolality of the solutions was measured before and after administration by the freezing point depression method with an advanced Digimatic osmometer, model $3 \mathrm{D} 11$. The $\mathrm{pH}$ of the solutions was measured with a unipolar $\mathrm{pH}$ electrode.

The paired $t$ test was used to evaluate the results. The study was approved by the Nottingham ethics committee and informed parental consent was obtained for investigations.

\section{DRUG OUTPUT FROM NEBULISERS}

In a separate series of experiments the distribution of sizes of aerosol particles from the nebulisers used was determined with a laser particle size analyser (Malvern Instruments, model 3600).

Before the particles reach the patient, they pass through $56 \mathrm{~cm}$ of tubing within the plelthysmograph. An exact model of these tubes (including the bends) was connected to the nebuliser chamber to ensure that the cloud that reached the laser was similar to the nebulised cloud that reached the patient. The nebulised cloud was pulled through the laser by a single stage liquid impinger run at a vacuum flow rate of $60 \mathrm{l} /$ minute.

A $2 \mathrm{ml}$ solution of $1 \%$ sodium cromoglycate was put into the reservoir of the Unicorn nebuliser chamber by pipette. The nebuliser was run for five minutes at $4.5 \mathrm{1} /$ minute and the aerosol cloud was drawn into the impinger device by a vacuum pump. The amount of anhydrous sodium cromoglycate collected in the single stage impinger was estimated by a spectropho-

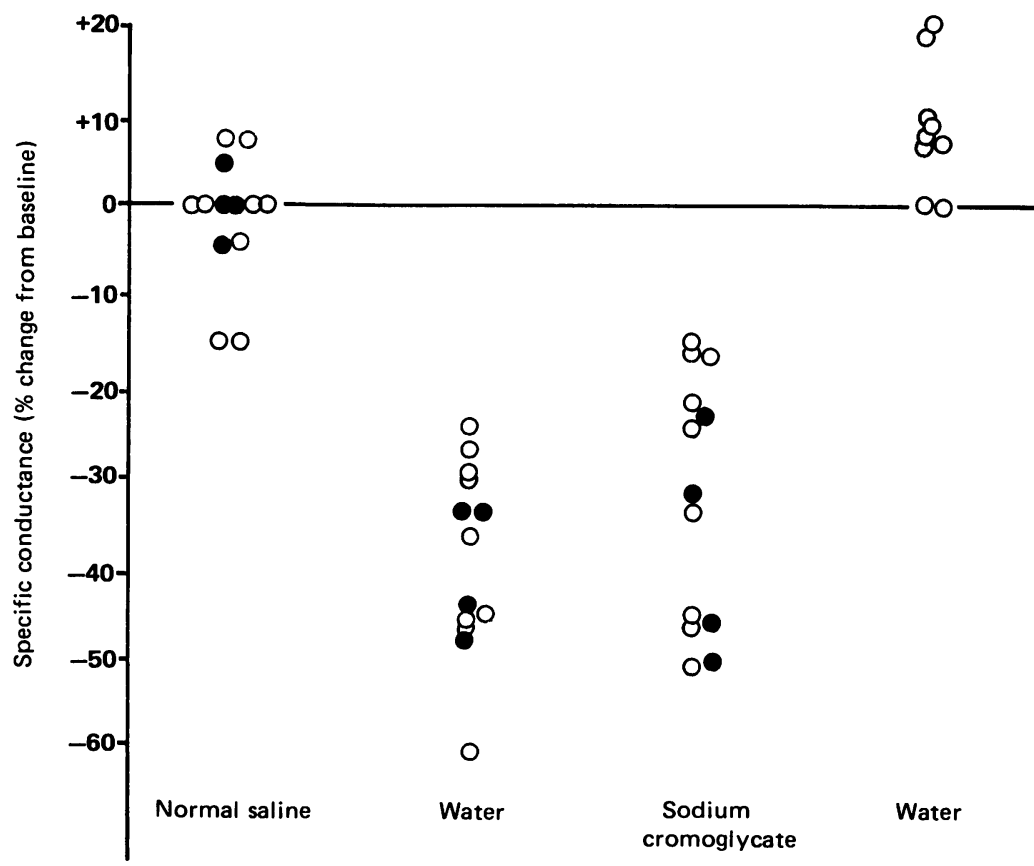

Results of nebulised challenges. tometric assay as previously described. The run was repeated eight times.

The following measurements were made: the mass median aerodynamic diameter (the diameter of droplets so that half of the aerosol mass is contained in smaller droplets and half in larger droplets), and the geometric standard deviation (SD) (the ratio of the $84 \cdot 1 \%$ diameter to the $50 \%$ mass median aerodynamic diameter). The value of the geometric SD is the measure of the width of droplet distribution.

The mass median diameter of the nebulised water and saline cloud were again calculated by the Malvern laser particle size device on eight occasions. The output from the nebuliser was calculated by weighing the nebuliser tubes before and after nebulisation.

\section{Results}

Only nine infants of the 13 completed the study. Their percentage change in specific conductance from baseline is shown in the figure (open circles). Four other patients woke up after being given nebulised sodium cromoglycate and were unable to complete the full study. The change in specific conductance in these patients after challenges with normal saline, water, and sodium cromoglycate are also shown in the figure (closed circles). If we consider the nine patients who completed the study, there was no significant change in lung function after challenge with normal saline. After challenge with nebulised water there was a significant decrease in specific conductance $(p<0 \cdot 001)$. After challenge with nebulised sodium cromoglycate there was also a significant decrease in specific conductance $(p<0.01)$, compared with values after receiving nebulised normal saline. The mean specific conductance of the group was $0.2(0.05)$ $\mathrm{cm} \mathrm{H}_{2} \mathrm{O}$ /second before the first nebulised water challenge and $0.19(0.05) \mathrm{cm} \mathrm{H}_{2} \mathrm{O} /$ second before the challenge with sodium cromoglycate. Fifteen minutes later the patients were challenged with nebulised water. On this occasion there was no significant change from the baseline measurement of specific conductance compared with the initial challenge with normal saline. The four patients who were challenged with a further four minutes of mist also showed no change in lung function.

Oxygen saturation was not monitored continously on paper during the study but did not drop below $80 \%$ at any time. The $\mathrm{pH}$ of nebulised sodium cromoglycate was $6 \cdot 8$, and the osmolality $60 \mathrm{mmol} / \mathrm{kg}$. Normal saline had an osmolality of $280 \mathrm{mmol} / \mathrm{kg}$ and a pH of $6 \cdot 7$. The osmolality of sodium cromoglycate increased to $70 \mathrm{mmol} / \mathrm{kg}$, and the osmolality of normal saline increased to $287 \mathrm{mmol} / \mathrm{kg}$, after nebulisation.

NEBULISER OUTPUT

The output of the nebulised saline and water are shown in table 2 . The mass median aerodynamic diameter of sodium cromoglycate from the Unicorn nebuliser chamber (run at a flow rate of 4.51 minute) was 4.5 microns (geometric SD $2 \cdot 5)$. The amount of sodium cromoglycate delivered in five minutes was $6.1 \mathrm{mg}$ to the face 
Table 2 Output characteristics of Variosonic nebuliser

\begin{tabular}{llll}
\hline & $\begin{array}{l}\text { Mass median } \\
\text { diameter }(\mu \mathrm{m})\end{array}$ & Geometric SD & $\begin{array}{l}\text { Mean }(S D) \\
\text { output/min } \\
(\mathrm{g})\end{array}$ \\
\hline $\begin{array}{l}\text { Distilled water } \\
\text { Saline } 0.9 \%\end{array}$ & 5.0 & 1.7 & $1.9(0 \cdot 1)$ \\
\hline
\end{tabular}

mask, and the amount of sodium cromoglycate lost from the nebuliser to the face mask was $1.8 \mathrm{mg}$.

\section{Discussion}

Challenge with nebulised water is a way of assessing bronchial reactivity in infancy. It enables us to assess the protective action of some of the drugs used in the treatment of asthma. The results of this study show that sodium cromoglycate protects the airways in infancy against the bronchoconstricting challenge of nebulised water. There was, however, transient bronchoconstriction after these infants were given nebulised sodium cromoglycate. We did not consider it ethical to sedate infants who were not ill for lung function studies, so we are unable to assess the effect of nebulised water or sodium cromoglycate in a control group.

Maximum bronchoconstriction in infants occurs during the first 10 minutes after challenge with nebulised water, and lung function has usually returned to the baseline measurement 15 minutes after challenge. ${ }^{3}$ The mechanism of water induced bronchospasm is not clear. Nebulised water increases lung epithelial permeability in both normal and asthmatic patients. ${ }^{6}$ In asthmatic patients, however, an increase in neutrophil chemotactic activity and histamine after challenge with nebulised water was found by Shaw et al. ${ }^{7}$

The sodium cromoglycate nebuliser solution caused transient bronchoconstriction in the lung function similar to that occurring after nebulised salbutamol is given. ${ }^{4}$ The sodium cromoglycate nebuliser solution is hypoosmolar, which may be responsible for the bronchoconstriction. Interestingly, iso-osmolar nebulised sodium cromoglycate has been shown to provide better protection against methacholine and exercise induced bronchoconstriction in adults than the hypo-osmolar solution commercially available. ${ }^{8}$ In adults there have only been isolated reports of bronchoconstriction after challenge with sodium cromoglycate. ${ }^{910}$

Because resistance to airflow increases inversely with the fourth power of the radius, the response to a bronchoconstricting stimulus could have a much greater effect on airflow resistance in the smaller airways of infants. There was a slight decrease in specific conductance compared with baseline values before challenge with water and before challenge with sodium cromoglycate. This may have augmented the response to the sodium cromoglycate. Nebulised water will also have reduced the tonicity of the airway secretions. This may have augmented the response to challenge with the hypo-osmolar nebulised sodium cromoglycate. Older children and adults with larger airways do not usually develop bronchoconstriction after nebulised sodium cromoglycate.
In contrast to our findings, Chung and Jones described the bronchodilator effect of sodium cromoglycate in children. ${ }^{11}$ They found that sodium cromoglycate produced significantly raised peak expiratory flow rates before exercise, which reached a maximum immediately after exercise. Sodium cromoglycate was given in a nebulised form. These results suggest that nebulised sodium cromoglycate inhibits the action of exercise induced bronchospasm, and causes bronchodilatation at the same time.

Allegra and Bianco found that in adults sodium cromoglycate prevented bronchoconstriction produced by ultrasonically nebulised distilled water. ${ }^{12}$ This was confirmed by Anderson et al in $1983 .{ }^{13}$ In our study nebulised sodium cromoglycate protected against the bronchoconstriction caused by nebulised water. It is unlikely that failure to induce bronchoconstriction with the second water challenge was the result of a refractory period following previous challenges. In a separate study of infants who developed bronchoconstriction after an initial challenge with water, only $20 \%$ were refractory to further challenges with water (unpublished observations). These results suggest that sodium cromoglycate must be reaching the lungs of these small infants.

The evidence that nebulised sodium cromoglycate does not work in infancy is sparse; it is our opinion that occasionally babies benefit from nebulised sodium cromoglycate. It is possible that with conventional nebulisers insufficient sodium cromoglycate enters the lungs. It is important therefore in future studies with nebulised sodium cromoglycate and other drugs in childhood that the particle size distribution of the aerosol delivered to the patient, and the amount of drug contained in various particle size factions, is published with the results so comparisons between studies may more readily be made.

1 Geller-Bernstein C, Levin S. Nebulised sodium cromoglycate in the treatment of wheezy bronchitis in infants and young children. Respiration 1982;43:294-8.

2 Henry RC, Hiller EJ, Milner AD, Hodges ICG, Stokes GM. Nebulised ipratropium bromide and sodium cromoglycate in the first two years of life. Arch Dis Child 1984;59:54-7.

3 O'Callaghan C, Milner AD, Swarbrick A. Nebulised salbutamol does have a protective effect on airways in children under 1 year old. Arch Dis Child 1988;63:479-83.

4 O'Callaghan C, Milner AD, Swarbrick A. Paradoxical deterioration in lung function after nebulised salbutamol in wheezy infants. Lancet 1986;i:1424-5.

5 Radford M. Measurement of airways resistance and thoracic gas volume in infancy. Arch Dis Child 1974;49:611-5.

6 Borland C, Chamberlan A, Barber B, Higginbottom T. Pulmonary epithelial permeability after inhaling saline, disPulmonary epithelial permeability after inhaling saline,
tilled water 'fog' and cold air. Chest $1985 ; 87: 373-6$.

7 Shaw RJ, Anderson SD, Durhams SR, et al. Mediators of hypersensitivity and fog-induced asthma. Allergy 1985;

8 Weiser P, Saaid M, Reshof A. Isotonic nebulised disodiumcromoglycate provides better protection against methacholine and exercise-induced bronchoconstriction. Am Rev Respir Dis 1988;137:1309-11.

9 Linzmayer I, Ishikama S. Disodium cromoglycate-induced bronchospasm in patients with asthma. Clin Res 1975; 23:599-617.

10 Johnson AJ. Bronchospasm due to the inhalation of disodium cromoglycate. Am Rev Respir Dis 1977;115:60.

11 Chung JTN, Jones RS. Bronchodilator effects of sodium cromoglycate and its clinical implications. $\mathrm{Br}$ Med $\mathcal{F} 1979$; ii: $1033-4$.

12 Allegra L, Bianco S. Non specific bronchial reactivity obtained with an ultrasonic aerosol of distilled water. Eur $\mathcal{F}$ Respir Dis 1980;61:41-9.

13 Anderson SD, Schoeffel RG, Finney M. Evaluation of ultrasonically nebulised solutions for provocation testing in patients with asthma. Thorax 1983;38:284-91. 